UDC 316.35

LBC 60.55

\title{
HUMAN RESOURCE RISKS OF FORMING PROFESSIONAL POTENTIAL OF SERVICEMEN
}

\author{
Irina Yu. Surkova \\ Povolzhsky institute of management - the Russian Presidential Academy of National Economy \\ and Public Administration, Saratov, Russian Federation
}

\begin{abstract}
The article analyzes the objective and subjective factors affecting the personnel risks of a military organization. The theoretical model for interpreting risks is based on several approaches. A realistic approach is used in the analysis of simulated (survival courses, military exercises) or real (military operations, counter-terrorism operations, deployments) hazard situations. Subjectively biased approach focuses on the problems of the attitude of military personnel to the distribution of resources, duties, and responsibilities within the organization. A socially constructed approach becomes a resource for analyzing constructs of risk situations created in the media or various communicative Internet sites (forums, chats) that do not always have a real embodiment. A socially mediated approach denotes vectors for the implementation of the main directions of the reform of the armed forces and the changes associated with them. The variability of risks is revealed to specific innovations in the future formation of a new look of the modern military. The context of discussions in professional network communities of the problems of retraining and advanced training of military personnel in "survival courses" is studied. The main risks associated with the formation of the professional potential of military personnel are "motivation risks" (expediency and prospects); "risks of professional incompetence" (unpreparedness, problems in organizing courses); "risks of inadequate official behavior" (gender relations, adaptive processes during trials). As a result, it is concluded that an intensive military training program is one form of minimizing the risks of professional incompetence. This program is used as a tool that reduces staff turnover during the first year of service, facilitates the work of the personnel service, and serves as an information springboard for the dissemination of knowledge about risk and its importance for professionalization among recruits.
\end{abstract}

Key words: human resource risks, professional potential, servicemen, special-to-arms course, military professional competences, gender relations.

УДК 316.35

ББК 60.55

\section{КАДРОВЫЕ РИСКИ ФОРМИРОВАНИЯ ПРОФЕССИОНАЛЬНОГО ПОТЕНЦИАЛА ВОЕННОСЛУЖАЩИХ}

\author{
Ирина Юрьевна Суркова \\ Поволжский институт управления им. П.А. Столыпина - филиал РАНХиГС при Президенте РФ, \\ г. Саратов, Российская Федерация
}

\footnotetext{
Аннотация. В статье анализируются объективные и субъективные факторы, влияющие на кадровые риски военной организации. Теоретическая модель интерпретации рисков базируется на нескольких подходах. Реалистический подход используется при анализе смоделированных (курсы выживания, боевые учения) или реальных (военные действия, контртеррористические операции, развертывания) ситуаций опасности. Субъективно предвзятый подход фокусируется на проблемах отношения военнослужащих к распределению ресурсов, обязанностей и ответственности внутри организации. Социально сконструированный подход становится ресурсом для анализа конструктов рисковых ситуаций, созданных в масс-медиа или различных коммуникативных интернет-площадках (форумах, чатах), не всегда имеющих реальное воплощение. Социально опосредованный подход обозначает векторы реализации основных направлений ре-
} 
формы вооруженных сил и сопряженных с ними изменений. Выявляется вариативность рисков применительно к конкретным нововведениям в перспективе формирования нового облика современного военного. Изучается контекст обсуждений в профессиональных сетевых сообществах проблем переподготовки и повышения квалификации военнослужащих на «курсах выживания». Основными рисками, сопутствующими формированию профессионального потенциала военнослужащих, являются «риски мотивации» (целесообразность и перспективы); «риски профессиональной некомпетентности» (неподготовленность, проблемы организации курсов); «риски неадекватного служебного поведения» (гендерные взаимоотношения, адаптивные процессы в ходе испытаний). В итоге делается вывод о том, что интенсивная программа подготовки военных представляет собой одну из форм минимизации рисков профессиональной некомпетентности. Эта программа используется как инструмент, понижающий текучесть кадров во время первого года службы, облегчает работу кадровой службы, служит информационным плацдармом для распространения среди рекрутов знаний о риске.

Ключевые слова: кадровые риски, профессиональный потенциал, военнослужащие, курсы подготовки, военно-профессиональные компетенции, гендерные взаимоотношения.

Нестабильная социально-экономическая обстановка на мировой арене, новые вызовы и угрозы России как со стороны международного терроризма, так и со стороны оппозиционных государств во многом оправдывают и доказывают необходимость масштабного реформирования вооруженных сил. Реорганизация военно-административной структуры, сокращение численности личного состава, модификация системы подготовки резервистов, гуманизация условий прохождения службы по призыву, перевод на аутсорсинг (обслуживание гражданскими организациями) системы обеспечения вооруженных сил фактически аккумулируют в себе ресурсы и создают базис для формирования кадрового потенциала вооруженных сил.

В социологических исследованиях неоднократно маркировался комплекс армейских проблем, привлекающих внимание как научного сообщества, так и управленческого аппарата [Смирнов 2010]. Эти проблемы в первую очередь касались перспектив формирования профессионального потенциала военнослужащих, а также кадровых рисков. Однако, если говорить о рисках в целом, важно концептуализировать данное понятие. В своих исследованиях Jens O. Zinn, раскрывая сущность рисков, выделял несколько ключевых позиций: реалистическую, субъективно предвзятую, социально опосредованную и социально сконструированную [Zinn 2008]. Так, с реалистической позиции риски связаны с реальными событиями или ситуациями опасности, которые оцениваются объективно и не зависят от субъективных социально-психологических факторов. С другой стороны, управ- ление рисками людей можно интерпретировать как «субъективно предвзятое», поскольку возможно точно выработать оптимальный ответ на риск, однако он будет трансформироваться в зависимости от внутреннего настроя, отношения к происходящему, аттитюдов. В то же время нельзя полностью игнорировать социальный контекст происходящих событий, что катализирует действие социальных факторов, влияющих на риск. И наконец, суждения и споры о риске могут возникать вне зависимости от реально существующей опасности.

Используя предложенную Jens O. Zinn теоретическую рамку, целесообразно проанализировать кадровые риски применительно к армейской службе. Как правило, они связаны с необоснованными решениями в системе распределения должностей, несоблюдением нагрузки военнослужащих, недостатками в области комплектования в гендерной перспективе, не всегда оптимальной подготовкой научных и управленческих кадров, экстренным характером произошедшего кадрового обновления с ужесточением требований, но без учета предыдущих заслуг [Суркова 2013]. Все аспекты, связанные с субъективной оценкой рисковой ситуации, справедливым / несправедливым распределением ресурсов и профессиональной ответственности, так или иначе подпадают под социально-предвзятый подход исследовательской оптики. Кадровые риски, которые зависят от реализации механизмов реформирования вооруженных сил, включающих оптимизацию штатной структуры, перераспределение служебной нагрузки, гендерное соотношение 
личного состава, актуализируют социально опосредованный подход. Несение воинской службы в районах боевых действий (независимо от того, как названа операция: принуждение к миру, поддержание мира, контртеррористическая операция и т. п.) или участие в смоделированной ситуации (курсы выживания, боевые учения и т. п.) проецируют кадровые риски в реалистичной перспективе. Обсуждение кадровых рисков и угроз в массмедиа, в том числе через интернет-коммуникации (чаты, форумы и т. п.), воспроизводит социальные конструкты, зачастую не связанные с реальностью.

Очевидно, что данные проблемы становятся серьезными рискогенными факторами эффективного исполнения вооруженными силами своих прямых задач обеспечения национальной безопасности страны, защиты от внешних и внутренних угроз. В связи с этим укрепление профессионального потенциала и преодоление кадровых рисков становится первоочередной задачей в системе управления вооруженными силами. При этом под профессиональным потенциалом понимается «система освоенных акторами военно-профессиональных знаний, умений, навыков, разделяемые принципы, ценности, нормы, позволяющие им осуществлять профессиональную деятельность, достигать властных полномочий, а также обеспечить карьерный рост и получение дохода» [Ершов 2016]. Все векторные направления армейского реформирования ориентированы на создание «нового облика вооруженных сил», который имеет конечной целью устойчивый профессиональный потенциал.

Однако конструированию системы профессиональных компетенций военной службы мешают барьеры в виде: кадровых рисков, которые можно представить потенциальными потерями или угрозами деятельности предприятия; вероятности нанесения организации ущерба в ходе принятия управленческого решения; неполучения ожидаемых результатов от действия или бездействия персонала [Митрофанова web]. Адаптируя терминологический подход к кадровым рискам учреждений и органов уголовно-исполнительной системы, предложенный А.Ю. Долининым [Долинин 2017], полагаем, что под кадровыми рисками вооруженных сил следует понимать вероят- ность снижения эффективности выполнения военнослужащими функций по поддержанию мира и защите государства от внешних и внутренних угроз, обусловленную внешними (неопределенностью и отсутствием стабильности в обществе, низким престижем службы в армии, негативным отношением населения, несистемными управленческими решениями реформирования силовых структур) и внутренними факторами (нерациональной системой управления персоналом и использования профессионального потенциала, отсутствием мотивации сотрудников к выполнению профессиональной деятельности). Безусловно, предложенный формат внешних и внутренних факторов, влияющих на кадровые риски, весьма условный, его можно расширять за счет множества конкретных примеров. Однако все они, так или иначе, касаются таких структурных компонентов, как противоречивость, неопределенность, опасность, уязвимость [Митрофанова web].

Полностью избавиться от кадровых рисков невозможно, они органично вплетены в повседневную жизнь любой организации или предприятия, однако возможно минимизировать их негативное воздействие на деятельность вооруженных сил. Для формирования оптимальной модели управленческой стратегии в контексте нивелирования последствий кадровых рисков в армии необходимо в первую очередь проанализировать вариативность этих рисков применительно к конкретным нововведениям в перспективе конструирования нового облика современного военного, способного эффективно выполнять свои задачи и противостоять рискогенности любой среды, в которую он реально или потенциально попадает.

В данной статье представлена попытка анализа кадровых рисков применительно к практике «тотальных курсов выживания». С этой целью были проанализированы посты, размещенные на специализированных форумах. Посты в форумах воплощаются в личных документах, представленных фактически анонимно в интернет-пространстве, поскольку персонификация происходит за счет ников. Для обобщения и структурирования информации об оценках субъектами гражданско-военных отношений одного из направлений реформиро- 
вания армии (в нашем случае - специальной военной подготовки военнослужащих по контракту) нами был использован метод контентанализа с последующим качественным анализом текста. Специфика данного подхода заключается в том, что основное содержание текста, представляя собой конгломерат всевозможных оценок, мнений и суждений, репрезентируется в рамках единой смысловой структуры [Mayring 2014]. Посты в форумах выступают инновационной коммуникативной формой, создаваемой и поддерживаемой дискурсивными сообществами через новые механизмы взаимодействия акторов даже закрытых социальных институтов. Анализ текстовых фрагментов выстраивался в традиционной логике от макро- к микротекстовому уровню через обобщение структурных свойств образцов текста (постов) и переход к оценкам в различных формах речевых актов, логическое объединение идей относительно кадровых рисков [Gruber 2008]. Цель данного исследования связана с попыткой отыскать индикаторы, указывающие на наличие в тексте тем, связанных с «курсами выживания», для последующего определения вариативности кадровых рисков.

Проблематика вариативности рисков и рефлексия рискового поведения военнослужащих репрезентирует достаточно серьезный пласт исследовательских инициатив в различных странах. Так, норвежские ученые Anders McD Sookermany, Trond Svela Sand и Gunnar Breivik, принимая участие в проекте «Обучение под угрозой», провели категориальный обзор исследований, касающихся рискованного поведения в контексте прохождения военной службы [Sookermany, Sand, Breivik web]. Данный проект был запущен для повышения знаний о риске и его значении для военных действий. Риски проявляются не только при участии в различного типа вооруженных конфликтах и операциях, но также значимы для успешной профессионализации (выработки профессиональных компетенций, связанных с готовностью к рискам). Обзор показал, что акцент в публикациях военной тематики в большей степени сделан на опыте и производстве рисков, тогда как моральные и экзистенциальные проблемы рефлексии рисков и готовности к ним представлены недостаточно. Чрезвычайно мало внимания уделяется проблемам обучения, способного развивать соответствующие формы поведения к различным видам риска. Таким обучением являются и «курсы выживания», о которых речь пойдет дальше. Бесспорно, особое внимание следует уделять культурным особенностям и гендерной составляющей при анализе кадровых и профессиональных рисков в силовых структурах.

Следуя классификации личностных кадровых рисков, предложенной И.В. Прониной [Пронина 2005], обозначим квалификационные риски, связанные с наличием у военнослужащих достаточного уровня знаний, навыков и опыта, необходимого для несения службы; риски мотивации, векторно обозначающие заинтересованность сотрудников в качественном и своевременном выполнении задач; риски потери трудоспособности (особенно актуально для военнослужащих) из-за отсутствия необходимого уровня безопасности выполнения профессиональных задач (собственная некомпетентность, рискогенная среда); криминальные риски, актуальные в контексте соблюдения тайны секретной информации.

Прохождение «курсов выживания» является необходимым условием формирования профессиональных компетенций, что позволяет нивелировать последствия в первую очередь «квалификационных рисков». Однако в отношении «рисков потери трудоспособности» мы имеем дело с бимодальной формой рисковой ситуации. С одной стороны, если потенциальный кандидат на момент заключения воинского контракта не прошел в полном объеме «курсы», он подвергает свою жизнь потенциальной опасности в будущем, поскольку армейское социальное пространство наполнено всевозможными угрозами и вероятностями участия в боевых действиях. С другой стороны, подобный формат развития компетенций, так необходимых военнослужащему, сопряжен с конгломератом новых рисковых ситуаций для здоровья и даже жизни во время прохождения самих «курсов выживания».

Риски мотивации в данном контексте также достаточно высоки, поскольку далеко не все военнослужащие позитивно воспринимают «курсы выживания». Эффективность данных мероприятий напрямую зависит от 
того, разделяют ли участники цели курсов, насколько они серьезно к ним относятся и насколько заинтересованы в качественном выполнении служебных заданий.

Итак, при формализованном анализе на первом этапе среди форумов, посвященных социальным процессам в армейской среде, был отобран тот, в котором репрезентировался опыт участия в курсах подготовки контрактников. На втором этапе все посты были разделены по тематическим приоритетам и вошли в единицы анализа. Анализ единиц счета по темам проводился с использованием интерпретативного подхода и фокусировался на рисках сотрудников вооруженных сил.

Итак, из всех проанализированных интерактивных площадок был отобран форум «Курсы выживания для контрактников» [Курсы... web], представленный 57 сообщениями. Эти сообщения можно разделить на следующие тематические приоритеты: процесс прохождения «курсов выживания», включая видеофрагменты (14); оценка эффективности (7); «гендерные особенности» (4); «организационные проблемы» (8); «предметы первой необходимости» (7); «целесообразность подготовки» (6); «перспективы службы по контракту» (3). Ocтальные посты из 57, размещенных на форуме, не несли серьезную смысловую нагрузку.

Соответственно, все перечисленные категории можно подразделить на укрупненные группы рисков персонала: «риски мотивации» (целесообразность и перспективы); «риски профессиональной некомпетентности» (неподготовленность, проблемы организации курсов); «риски неадекватного служебного поведения» (гендерные взаимоотношения, адаптивные процессы в ходе испытаний).

Лишь несколько сообщений (4) были связаны с оценкой тяжести прохождения курсов: «Жить можно, я тоже прошел» (рядовой, мужчина); «Дааа... Я тоже прошла школу выживания! 1,5 месяца обращались, как с курсантами. Но главное - выполнять и пеpeтерпеть!» (рядовой, женщина). В данном случае речь идет о рутинизации практик «курсов выживания», когда оценка трудностей прохождения испытаний адекватна требованиям освоения воинской профессии.

Встречались достаточно подробные сообщения с акцентом на конкретные процедур- ные моменты (3): «Гоняют, как молодых. В день по 15 км бегали. На учебные места всегда бегом. Конспекты пишешь стоя. Отночение, как к срочнику. Я за 1,5 месяца 15 кг сбросил... Все прошедшие дни кажутся тебе лафой, но продержаться можно» (рядовой, мужчина). «Самые сложные, тяжелье чисто физически - занятия в поле. Они включают в себя марш в пешем порядке до пятидесяти километров, мари-броски в полной экипировке на 10 км. С преодолением огнево-штурмовой полоcbl, и много еще чего» (сержант, мужчина). Те кандидаты, которые не справляются с препятствиями, автоматически испытывают на себе риски профессиональной некомпетентности, обусловленные низким качеством выполнения обязанностей, нежеланием подчиняться вышестоящему руководству, опасными действиями, которыми можно навредить собственному здоровью, а также здоровью сослуживцев .

Часть постов касалась гендерной составляющей практики введения «курсов выживания». Здесь мнения разделились. Часть пользователей считают, что подобные курсы для женщин вполне приемлемы и их необходимо проходить всем: «С курсов выживания вернулись. На этот счет была телеграмма - читала лично: раз в 3 года! Так что те, кто еще не проходил, встряли» (лейтенант, женщина). Другая часть полагала, что от таких испытаний женщин необходимо ограждать: «Почему женщчин на 34-градусной жаре заставляют рыть окопы? Шесть человек вчера потеряли сознание, а срочников держат по казармам? Наверное, потому, что командование боится Комитета солдатских матерей... Может, пора создать комитет солдатских мужей? Почему неподготовленных женщин заставляют проходить полосу препятствий, они при этом ломают ноги и им же объявляют выговоры...» (рядовой, мужчина). Обратим внимание, что в данном посте речь идет о серьезной физической неподготовленности части женщин к таким мероприятиям. С одной стороны, это, безусловно, проблема самих кандидатов, которые не имеют достаточных навыков для замещения определенных должностей в армии, а с другой, речь идет о про- 
блеме организации самих курсов, когда в сложные условия «выживания» помещаются неподготовленные женщины, что чревато проблемами с их здоровьем.

В следующих постах встречаются замечания относительно организационных проблем реализации «курсов выживания», которые выходят за пределы личной ответственности претендентов на контракт и попадают в зону ответственности части: «Контингент, который приходит для прохождения программы интенсивной подготовки, $80 \%$ не готов к данным курсам, я бы сказал, не то что морально, но и материально. Многие приходят на обучение без снаряжения, совершенно не знакомы с их устройством, например, сколько шпиньков должно быть на ОЗК, как из шести плащ-палаток собрать палатку на отделение, и т. д. ... Программа сырая» (рядовой, мужчина); «До сих пор непонятно, почему курсы выжсивания... И курсы выживания непонятно для чего))) Только в нашей армии могут послать военнослужащего на курсы или еще кудалибо неподготовленным... Вещевку и некоторое обмундирование не положено - покупайте сами...» (рядовой, мужчина). Приведенные в пример посты свидетельствуют о том, что у многих военнослужащих нет достаточно четкого осознания необходимости «курсов выживания», что апеллирует к рискам низкой мотивации, отсутствию желания самостоятельной подготовки к прохождению препятствий, что, в свою очередь, влияет на уровень освоения компетенций.

Еще 7 постов были посвящены обсуждению того, что необходимо брать с собой для прохождения курсов: «Учитывая, что в Интернете есть информация уровня - никто выживальщиков никакой амуницией не обеспечивает, то что бы посоветовали уже прошедшие курсы брать с собой? Что из экипировки... что из “бытового”?» (рядовой, мужчина). В ответах встречались достаточно подробные описания: «1) возьмите с собой аптечку, в нее положите пластырь для мозолей, клей для заклечвания открыmых ран (после копания окопов), антибиотики, средство от диареи, витамины, так как организм испьтывает большие нагруз$\kappa и$; 2) сменная одежда, можно старую, чтобы после того, как поползаешь на животе, можно было в казарме переодеться в чистое; 3) взять облегченные бериы со вставками из ткани, а к ним взять много портянок и носков» (сержант, мужчина). В следующем посте дается дополнительное уточнение: «...3anacumecь фляжкой для воды, иначе вас ждет смерть. Что-нибудь типа плащ-палатки, просто она легкая и компактная. Обязательно берите нож. Фонарик еще возьмите, ночью и в темных местах он незаменим. Еще какую-нибудь мазь от комаров, а то достанут хлеще самих курсов» (рядовой, мужчина). Такой детальный перечень предметов первой необходимости создает впечатление, что в центpax подготовки абсолютно отсутствует система обеспечения претендентов на контракт, включая элементарную медицинскую помощь. Опять же налицо серьезные пробелы в управлении социальными процессами на «курcax выживания». Уточнения типа «вас съедят комары» или «иначе смерть от жаж$\partial b l »$ указывают на элементарные проблемы в бытовых условиях. Подобные факторы вполне могут спровоцировать риски деструктивного поведения, вплоть до воровства.

Более того, встречались достаточно серьезные критические замечания, направленные на оценку целесообразности подобной подготовки для всех без исключения военнослужащих контрактной службы. «Kypcы bыживания - дело, конечно, хорошее, но, на мой взгляд, вынос и позиционирование именно как отдельный курс - дело не совсем правильное... Гораздо эффективнее, продуктивнее, с большей пользой было бы вынести эти курсы, так сказать, в повседневность военнослужсаших в общем иконтрактников в частности... проведение этих курсов 1 раз в год-это то же самое, что 1 раз в год сходить на стрельбище или 1 раз в год позаниматься строевой или физо... позаниматься, вроде бы позанимался, а толку мало...» (лейтенант, мужчина). «Понятно, если боец пришел на контракт и ему надо курсы типа КМБ. Но когда привлекают старшину роты (прапоршика), которому уже за 40, или женщин, у которых есть несовершеннолетние дети и которым также под 40 лет - не понятно. 
И.Ю. Суркова. Кадровые риски формирования профессионального потенциала военнослужащих

Старшина сам кого хочешь чему угодно научит. А спечиальности за это время какой можно научиться - окопокопатель, ОЗК-надеватель?.. Есть же боевая подготовка в частях, на местах. Людей отрывают от исполнения служебных обязанностей, от несения вахт, дежурств... Ну а военнослужашим женщинам, кому за 40 и которым через год-два в запас, -им это зачем?» (лейтенант, мужчина). «Не понимаю смысл этого КМБ. Ну а что за 3 недели, что за 6 недель супербойца не сделаешь, эта чушь сделана для дальнейшего просеивания личного состава...» (рядовой, мужчина).

Таким образом, основная критика связана с тотальной практикой направления на «курсы выживания» всего личного состава, тогда как достаточно большая часть военнослужащих, например в ближайшем будущем подлежащим увольнению в запас, такой экстрим не обязателен. Гендерные проблемы также поднимаются, с одной стороны, в связи с тем, что у многих женщин-военнослужащих есть несовершеннолетние дети, нуждающиеся в постоянной заботе, а подобные курсы мешают исполнению надлежащего ухода. С другой стороны, отсутствие нормальных бытовых условий фактически является серьезным препятствием для исполнения женщинами своих профессиональных обязанностей.

Однако встречались сообщения позитивного характера, оправдывающие тяжелые условия подобной системы подготовки: «Ведь это курсы военного назначения и по поводу “ванны”", как некоторые здесь пишут, можно на самом деле на некоторое время забыть. В число первой обеспеченности входит определенный состав материалов и продуктов питания, которым, как показывает практика, военное ведомство обеспечивает на все сто проиентов. Можно войти в ситуачию и понять задержки с некоторой частотой, но это не столько критично... Для контрактных военнослужаших это хорошая школа выживания» (рядовой, мужчина). «Курсы выюивания для военнослужащих должны быть чаще, это же реальная возможность получить практические навыки жизни в тех условиях, в которых ты оказался. Да, на таких курсах всегда очень сложно: ежечасная повышенная физическая и эмочиональная нагрузка, необходимость быть максимально собранным, действовать во всем (даже в мелочах) рационально и соблюдать воинскую дисциплину. Служба в части (в обычных условиях) бывалого контрактника часто расхолаживает, он всячески старается избежать лишней нагрузки, возлагая ее на других, но какая же это служба? Ношение формы военнослужащего - не всегда признак высоких воинских навыков, отличной физической подготовки, а она совершенно необходима, так я уверен. Армия обязана быть в состоянии высокой готовности, иначе она становится малоспособной действовать в случае необходимости. Уважают сильных...» (рядовой, мужчина). Соответственно, в этих сообщениях формулируются утверждения-требования для военнослужащих как особой профессиональной группы людей, чей жизненный мир подчинен не только рутинным обязанностям, но и форсмажорным обстоятельствам, связанным с защитой Родины. Поэтому претензии на комфорт - это формат «риска неадекватного поведения» в сложных условиях «выживания», поскольку профессия военнослужащего априори входит в категорию рисковых.

Кроме того, встретились 3 поста, в которых указывалось на то, что служба по контракту является декларативной формой привлечения в ряды вооруженных сил, а на самом деле на практике перспективы службы в армии не такие радужные. Испытав на себе все радости «курсов выживания», военнослужащие имеют «з/n 17 000, мы полгода в поле сидим, дров нет, бензин на генератор за свои, холодина в палатке, неимоверная жратва, отстой, я уже забыл, что такое ванна» (рядовой, мужчина). Как мы видим, опять идет акцент на несовершенство в организационном процессе контрактной службы, сложности с эффективным управлением и обеспечением военнослужащих-контрактников.

Таким образом, анализ показал, что интерактивное обсуждение в Интернете на площадках, посвященных социальным процессам в армии, достаточно популярно и затрагивает одно из направлений реформирования Воору- 
женных сил Российской Федерации - профессиональную переподготовку и повышение квалификации военнослужащих, актуализируя проблему кадровых рисков. Основной дискурс обсуждений сосредоточился на принципиальных вопросах необходимости «курсов выживания» для всех категорий военнослужащих и на социальных проблемах организации и управления этими курсами, маркировавших проблемы слабой материальной обеспеченности и перекладывание ответственности за экипировку, предметы первой необходимости и медикаменты на самих претендентов на заключение контракта. Гендерный формат был представлен противоречивыми рассуждениями, направленными, с одной стороны, на критику современных «курсов выживания», которые вынуждены проходить неподготовленные ни в физическом, ни в моральном, ни в бытовом плане женщины, а с другой - необходимость унификации требований подготовки военнослужащих, не взирая на половую принадлежность.

На одной из интернет-площадок, посвященных юридической помощи призывникам и военнослужащим, был проведен анализ ситуации с курсами интенсивной военной подготовки для контрактников в 2019 г., в котором акцентируется внимание на двух ключевых проблемах: коррупции (варианты номинального прохождения курсов без фактического участия) и экипировке (проблемы оснащения «стажеров» необходимым обмундированием, практики приобретения необходимых вещей за свой счет) [Как проводятся курсы... web]. Формат сайта носит не научный характер, а публицистический, представляющий площадку для проявления активной гражданской позиции, что вполне соответствует целям данной статьи, аккумулирующей репрезентации мнений населения, как гражданских лиц, так и представителей армейского социума, относительно оценки рисковых ситуаций в формировании профессионального потенциала военнослужащих. В результате можно зафиксировать неисчезающую со временем проблему обмундирования и экипировки граждан, проходящих курсы интенсивной военной подготовки.

Итак, фактически «курсы выживания» это одна из форм минимизации рисков «про- фессиональной некомпетентности», позволяющей на ранних этапах выявить кандидатов, не сумевших освоить необходимый уровень компетенций военнослужащих контрактной службы, а также определить кандидатов, транслирующих не всегда адекватное поведение в сложных психологических и физических условиях. Это помогает в дальнейшем избежать оттока кадров, увольняемых на первом году службы из-за непомерных нагрузок и психологического прессинга. Однако подобный анализ форумов вскрывает и внешние факторы, провоцирующие объективные показатели неудовлетворенности личного состава форматом испытаний и подготовки к военной службе определенного уровня, фактически выступая превентивной стратегией противодействия кадровым рискам.

\section{СПИСОК ЛИТЕРАТУРЫ}

Долинин 2017 - Долинин А.Ю. Кадровые риски учреждений и органов уголовно-исполнительной системы // Уголовно-исполнительное право. 2017. № 1. С. 56-61.

Ершов 2016 - Ершов B.B. Трансформация профессионального потенциала военнослужащих, проходящих военную службу по контракту: дис. ... канд. социол. наук. Саратов, 2016.

Как проводятся курсы... web - Как проводятся курсы выживания для контрактников в 2019 году [Помощь призывникам и военнослужащим] // http://armiyahelp.ru/kontrakt/kakprovodyatsya-kursy-vyzhivaniya-dlyakontraktnikov-v-2017-godu.html.

Курсы... web - Курсы выжсивания для контрактников в 2015-2016 году [Форум Министерства обороны Российской Федерации] // http:// www.forum-mil.ru/forum/116-1018-3.

Митрофанова web-Митрофанова A.E. Социально-экономическое содержание и структура кадровых рисков в организации [Вестник Московского государственного областного университета. 2013. № 2] // https://evestnikmgou.ru/ru/Articles/Doc/317.

Пронина 2005 - Пронина И.В. Оценка компетенций персонала промышленного предприятия при принятии управленческих решений: дис. ... канд. экон. наук. Ижевск, 2005.

Смирнов 2010 - Смирнов А.И. Взаимодействие общества и армии как социального института в современной России: монография. М.: Ин-т социологии РАН, 2010. 
Суркова 2013 - Суркова И.Ю. Социальная политика в системе гражданско-военных отношений: монография. М.: ООО «Вариант», ЦСПГИ, 2013.

Gruber 2008 - Gruber H. Analyzing Communication in the New Media // Qualitative Discourse Analysis in the Social Sciences / ed. by Wodak R., Krzyzanowski. M.: Basingstoke: Palgrave Macmillan, 2008.

Mayring 2014 - Mayring P. Qualitative content analysis: theoretical foundation, basic procedures and software solution. Klagenfurt: Beltz, 2014.

Sookermany, Sand, Breivik web - Sookermany McD, Sand T.S., Breivik G. Risk-Taking Attitudes And Behaviors Among Military Personnel In Dangerous Contexts [A Categorized Research Bibliography, Oslo: Norwegian School of Sport Sciences Defence Institute. 2015] // https:// www.researchgate.net/publication/277597805 Risk-taking_attitudes_and_behaviors among_military_personnel_in_dangerous contexts_A_categorized_research_bibliography.

Zinn 2008 - Zinn J.O. Social Theories of risk and uncertainty. An Introduction. Oxford; Malden, MA: Blackwell Publishing, 2008.

\section{REFERENCES}

Dolinin A.Yu., 2017. Personnel risks of institutions and bodies of the penal correction system. Penal enforcement law, no. 1, pp. 56-61.

Ershov V.V., 2016. Transformation of professional potential of military personnel performing military service under contract. Cand. sociol. diss. Saratov.

How are the survival courses for contractors conducted in 2019. URL: http://armiyahelp.ru/ kontrakt/kak-provodyatsya-kursy-vyzhivaniyadlya-kontraktnikov-v-2017-godu.html.
Survival courses for contractors in 2015-2016. Forum of the Ministry of Defence of the Russian Federation. URL: http://www.forum-mil.ru/ forum/116-1018-3.

Mitrofanova A.E., 2013. Socio-economic content and structure of personnel risks in the organization. Journal of the Moscow State Regional University, no. 2. URL: https://evestnik-mgou.ru/ $\mathrm{ru} /$ Articles/Doc/317.

Pronina I.V., 2005. Evaluation of competence of industrial enterprise personnel in making management decisions. Cand. econ. diss. Izhevsk.

Smirnov A.I., 2010. Interaction between society and the army as a social institution in modern Russia: monograph. Moscow, In-t of sociology of RAS.

Surkova I.Y., 2013. Social policy in the system of civilmilitary relations: monograph. Moscow, LLC "Option", TsSPGI.

Gruber H., 2008. Analyzing Communication in the New Media. Qualitative Discourse Analysis in the Social Sciences. Moscow, Basingstoke, Palgrave Macmillan.

Mayring P., 2014. Qualitative content analysis: theoretical foundation, basic procedures and software solution. Klagenfurt, Beltz.

SookermanyMcD, Sand T.S., Breivik G., 2015. Risk-Taking Attitudes And Behaviors Among Military Personnel In Dangerous Contexts. A Categorized Research Bibliography. Oslo, Norwegian School of Sport Sciences Defence Institute. URL: https:// www.researchgate.net/publication/277597805 Risktaking_attitudes_and_behaviors_among_ military_personnel_in_dangerous_contexts A_categorized_research_bibliography.

Zinn J.O., 2008. Social Theories of risk and uncertainty. An Introduction. Oxford; Malden, MA, Blackwell Publishing.

\section{Information About the Author}

Irina Yu. Surkova, Doctor of Sciences (Sociology), Professor of the Department of Human Resource Management, Povolzhsky Institute of Management - the Russian Presidential Academy of National Economy and Public Administration, Sobornaya St., 23/25, 410031 Saratov, Russian Federation, irina_surkova@mail.ru,https://orcid.org/0000-0002-5483-0128

\section{Информация об авторе}

Ирина Юрьевна Суркова, доктор социологических наук, профессор кафедры управления персоналом, Поволжский институт управления им. П.А. Столыпина - филиал РАНХиГС при Президенте РФ, ул. Соборная, 23/25, 410031 г. Саратов, Российская Федерация, irina_surkova@mail.ru, https://orcid.org/0000-0002-5483-0128 